\title{
Expectant management of early-onset severe preeclampsia: a principal component analysis
}

\author{
Yiping Le, Jing Ye, Jianhua Lin \\ Department of Obstetrics and Gynecology, Renji Hospital, School of Medicine, Shanghai Jiaotong University, Shanghai 200127, China \\ Contributions: (I) Conception and design: J Lin; (II) Administrative support: None; (III) Provision of study materials or patients: Y Le, J Lin; (IV) \\ Collection and assembly of data: Y Le, J Ye; (V) Data analysis and interpretation: Y Le, J Ye; (VI) Manuscript writing: All authors; (VII) Final \\ approval of manuscript: All authors. \\ Correspondence to: Jianhua Lin. Department of Obstetrics and Gynecology, Renji Hospital, School of Medicine, Shanghai Jiaotong University, Pujian \\ Road 160, Shanghai 200127, China. Email: linjhuarj@126.com.
}

\begin{abstract}
Background: Preeclampsia is a multisystem disorder that is characterized by hypertension with either proteinuria or end-organ dysfunction in both previously normotensive women and chronically hypertensive women. To identify the important influencing factors for early-onset severe preeclampsia, this study undertook to explore the associations between preeclampsia characteristics, along with the decreased latency and poor neonatal outcomes during expectant management of severe preeclampsia before 34 weeks of gestation.

Methods: A total of 213 patients were retrospectively studied. Pregnancy outcomes in terms of maternal complications and neonatal outcomes were determined. Statistical analysis was performed by principal component analysis, Student's $t$-test, and Pearson correlation analysis.

Results: Neonatal mortality was influenced by gestational age at delivery and birth weight. The main factors that influenced pregnancy outcome were gestational age at diagnosis, the 24-h urine protein level, the plasma albumin level, and hydrothorax plus ascites. When the gestational age at diagnosis was 25 weeks, and 4/7 days, the probability that the pregnancy would be classified into group 2 with $79.3 \%$ neonatal survival was almost 50\%. Only the plasma albumin level and hydrothorax plus ascites affected prolongation.

Conclusions: Plasma albumin level and hydrothorax plus ascites should be considered seriously, as they may be a reason to terminate the expectant management of early-onset severe preeclampsia. Given its unsatisfactory pregnancy outcomes, expectant management should be reconsidered before 25 weeks and 4/7 days.
\end{abstract}

Keywords: Expectant management; early-onset severe preeclampsia; pregnancy outcome; principal component analysis

Submitted Jun 18, 2019. Accepted for publication Sep 23, 2019.

doi: 10.21037/atm.2019.10.11

View this article at: http://dx.doi.org/10.21037/atm.2019.10.11

\section{Introduction}

Preeclampsia is a multisystem disorder that is characterized by hypertension with either proteinuria or end-organ dysfunction in both previously normotensive women and chronically hypertensive women (1). The exact vasoactive molecule responsible for preeclampsia has not yet been determined, but it is widely accepted that the placenta plays a crucial role in the pathogenesis of preeclampsia and that delivery of the placenta remains the only definitive treatment (2). However, the delivery may not be in the best interest of the fetus when the gestational age is below 34 weeks, mainly because of the immaturity of the fetal lung (3). The policy of expectant management was proposed to improve neonatal outcomes; however, the course of preeclampsia, especially early-onset severe preeclampsia, which is defined as preeclampsia that occurs prior to 34 weeks of gestation, is associated with progressive deterioration of the maternal condition (4). Therefore, the tipping point in terms of the risks and benefits of expectant management must be determined. 
This study was undertaken to explore the associations between preeclampsia characteristics and examine the decreased latency and poor neonatal outcomes during the expectant management of early-onset severe preeclampsia, with data stratified according to pregnancy outcome due to difficulties in evaluating different maternal and neonatal complications.

\section{Methods}

\section{Study subjects}

We performed a retrospective review of all 213 women with severe preeclampsia diagnosed at $<34$ weeks of gestation who received expectant management to prolong pregnancy and who were admitted between 2010 and 2015 at Renji Hospital affiliated with Shanghai Jiaotong University School of Medicine. This study was approved by the ethics review board of Renji Hospital affiliated with Shanghai Jiaotong University School of Medicine, and informed consent was obtained from every patient. The inclusion criteria were as follows: the diagnosis of severe preeclampsia of pregnancies was performed according to the American College of Obstetricians and Gynecologist (ACOG) criteria (1). The exclusion criteria were as follows: the condition of either the mother or fetus was unstable during the first 48 hours after admission. Specifically, this included women with eclampsia, HELLP syndrome, severe uncontrolled hypertension (defined as the inability to stabilize systolic blood pressure $<160 \mathrm{mmHg}$ and diastolic pressure $<110 \mathrm{mmHg}$ when maxed out on antihypertensive drugs), abruptio placentae, an abnormal fetal heart rate, severe oligohydramnios (defined as the deepest vertical pocket being $<2 \mathrm{~cm}$ or an amniotic fluid index $<5 \mathrm{~cm}$ ) or reversed end-diastolic flow in the umbilical artery. Nine patients were diagnosed with severe preeclampsia before 24 weeks and still insisted on continuing the pregnancy because of sterility or recurrent spontaneous abortion. The authors are accountable for all aspects of the work in ensuring that questions related to the accuracy or integrity of any part of the work are appropriately investigated and resolved.

\section{Expectant management}

Prophylactic magnesium sulfate was given in the first 5 days of expectant management, intrapartum, and for 48-72 hours postpartum. Dexamethasone was given when the patient was admitted to the hospital. Maternal monitoring included blood pressure measurements every 6 hours, clinical evaluations of symptoms a minimum of two times a day, and 24-hour urine analysis twice weekly. Antihypertensive drugs such as labetalol and nifedipine were used to maintain systolic blood pressure at $155 \mathrm{mmHg}$ or lower and diastolic blood pressure at $100 \mathrm{mmHg}$ or lower. Intravenous nicardipine was used as a first-line treatment for women with severe hypertension (defined as systolic blood pressure $\geq 160 \mathrm{mmHg}$ or diastolic blood pressure $\geq 110 \mathrm{mmHg}$ ). When necessary, labetalol, nifedipine, and nicardipine were used together. Blood tests included measurements of hemoglobin, platelet counts, liver enzymes [aspartate transaminase (AST) and alanine aminotransferase (ALT)], creatinine, lactate dehydrogenase, fibrinogen, D-dimers, prothrombin times, and partial thromboplastin times. These tests were performed daily, every other day, or once every three days, depending on the clinical symptoms and laboratory findings. Fetal evaluations included ultrasound evaluations of fetal growth and estimations of amniotic fluid volume at entry, umbilical artery Doppler velocimetry, fetal heart rate monitoring, and clinical evaluations of fetal movement three times a day.

\section{Fetal and maternal complications and indications of delivery}

Fetal indications of delivery during expectant management were an abnormal fetal heart rate monitoring (repeated late decelerations or decreased long-term variability), severe intrauterine growth retardation (IUGR), absent or reversed end-diastolic flow on umbilical artery Doppler imaging, and oligohydramnios.

Maternal indications for delivery during expectant management were all major maternal complications defined below, except for severe uncontrolled hypertension despite maximum doses of combined antihypertensive therapy (labetalol, nifedipine, and nicardipine), and thrombocytopenia $(<100,000$ cells $/ \mu \mathrm{L})$.

Major maternal complications included maternal death, eclampsia, HELLP syndrome, abruptio placentae, disseminated intravascular coagulopathy (DIC), pulmonary edema, and acute renal failure. HELLP syndrome was defined as the presence of all 3 of the following criteria: hemolysis [characteristic peripheral blood smear and serum lactate dehydrogenase (LDH) $\geq 600 \mathrm{U} / \mathrm{L}$ or serum total bilirubin $\geq 1.2 \mathrm{mg} / \mathrm{dL}$ ], elevated liver enzymes (serum ALT $\geq 70 \mathrm{U} / \mathrm{L})$, and low platelet counts $(<100,000$ cells $/ \mu \mathrm{L})$. DIC was defined as the presence of 3 or more of the 
Table 1 Group categories

\begin{tabular}{llrc}
\hline Group & Fetal outcomes & $\mathrm{n}$ & $\begin{array}{c}\text { Neonatal } \\
\text { survival (\%) }\end{array}$ \\
\hline 1 & Fetal loss & 46 & $0(0)$ \\
2 & Live birth $<34$ weeks & 116 & $92(79.3)$ \\
$2 \mathrm{a}$ & Due to the maternal indications & 38 & $32(84.2)$ \\
$2 \mathrm{~b}$ & Due to the fetal indications & 78 & $60(76.9)$ \\
3 & Live birth $\geq 34$ weeks & 50 & $50(100.0)$ \\
\hline
\end{tabular}

Table 2 Influencing factors in terms of neonatal mortality

\begin{tabular}{lcccc}
\hline $\begin{array}{l}\text { Neonatal } \\
\text { outcomes }\end{array}$ & $\begin{array}{c}\text { GA at delivery } \\
\text { (day) }\end{array}$ & $\begin{array}{c}\text { GA diagnosis } \\
\text { (day) }\end{array}$ & Prolongation & $\begin{array}{c}\text { Birth } \\
\text { weight* }\end{array}$ \\
\hline $\begin{array}{l}\text { Neonatal } \\
\text { survival }\end{array}$ & 221.5 & 203.6 & 17.4 & $1,369.5$ \\
$\begin{array}{l}\text { Neonatal } \\
\text { death }\end{array}$ & 210.9 & 198.2 & 12.9 & $1,045.0$ \\
\hline
\end{tabular}

*, $\mathrm{P}<0.05$ between the two groups.

following criteria: low platelet counts $(<100,000$ cells $/ \mu L)$, low fibrinogen $(<300 \mathrm{mg} / \mathrm{dL})$, being positive for D-dimers ( $\geq 50 \mathrm{mg} / \mathrm{dL}$ ) or prolonged prothrombin ( $\geq 14$ seconds), and partial thromboplastin ( $\geq 40$ seconds) times. Pulmonary edema was diagnosed on the basis of clinical findings and chest radiography. Acute renal failure was diagnosed in the presence of oliguria or anuria in association with elevated serum creatinine levels greater than $120 \mu \mathrm{mol} / \mathrm{L}$ $(>1.4 \mathrm{mg} / \mathrm{dL})$. The need for dialysis was considered when a severe renal failure occurred.

\section{Criteria of patients group}

There was one case of maternal death, which was brain hemorrhage due to the sudden uncontrolled hypertension. The remaining 212 patients were divided into 3 groups according to fetal outcomes, which was shown in Table 1. The definition of fetal loss and live birth were as follows: fetal loss, including intrauterine fetal death, and termination of midtrimester pregnancy due to disease severity; live birth, birth with a living child. We further divided this condition into 2 parts: $<34$ weeks and $\geq 34$ weeks. Based on the indications of delivery, the 2 nd group was divided into $2 \mathrm{a}$ and $2 \mathrm{~b}$. We also observed the neonatal survival rate of all 3 groups, which means the survival rate of live births during the first 28 completed days.

\section{Statistical analysis}

Data are presented as the average and range or percentage, as appropriate. All variables were analyzed separately. Multivariate regression analysis was performed to investigate the contributions of IUGR (5); prolongation; the gestational ages at the time of diagnosis and delivery; the platelet count; liver enzyme levels (ALT); plasma albumin; creatinine; 24-hour urine protein; doses of antihypertensive drugs; and pleural fluid and ascites for pregnancy outcomes in group $1,2 \mathrm{a}, 2 \mathrm{~b}$, and 3 . The remaining statistical analyses were performed by Student's $t$-test and Pearson correlation analysis.

\section{Results}

\section{Characteristics summary}

During the study period, 213 singleton pregnancies were admitted for preeclampsia and expectantly managed from 17 weeks and $0 / 7$ days to 33 weeks and $5 / 7$ days.

\section{Fetal and neonatal outcomes}

In total, $166(80 \%)$ infants were born alive. The average gestational age at diagnosis of these infants was 27 weeks and $6 / 7$ days; the average birth weight was $1,582 \mathrm{~g}$. Neonatal mortality for live births was $14.5 \%$, which was influenced by gestational age at delivery and birth weight, as shown in Table 2. Fetal death occurred before delivery at an average gestational age of 26.8 weeks, and the average birth weight of these infants was $850 \mathrm{~g}$.

\section{Maternal outcome}

The average number of days of pregnancy prolongation days was 18.5 days. Delivery was achieved by cesarean section in $79.2 \%$ of cases. Deliveries were prompted by maternal reasons in $39.6 \%$ of cases, fetal distress in $45.3 \%$ of cases, and a combination of the two in $15.1 \%$ of cases. The 1 case of maternal death was due to brain hemorrhage because of sudden uncontrolled hypertension. There were no instances of eclampsia or severe acute renal failure among the 213 women.

\section{Influencing factors to pregnancy outcome}

By using the multivariate regression analysis, Table 3 shows the main effects of multiple factors on the three groups. In group 1, the main factor was gestational age at diagnosis. 
Table 3 Contributions of factors to the pregnancy outcomes

\begin{tabular}{lccccccccccc}
\hline Group IUGR & $\begin{array}{c}\text { Liver } \\
\text { enzyme }\end{array}$ & Creatinine & Platelet $\begin{array}{c}\text { 24-h urine } \\
\text { protein }\end{array}$ & Albumin & $\begin{array}{c}\text { Hydrothorax } \\
\text { and ascites }\end{array}$ & $\begin{array}{c}\text { GA at } \\
\text { diagnosis }\end{array}$ & $\begin{array}{c}\text { GA at } \\
\text { delivery }\end{array}$ & $\begin{array}{c}\text { Prolongation } \\
\text { Antihypertensive } \\
\text { therapy }\end{array}$ \\
\hline 1 & 0.20 & 0.31 & 0.24 & 0.11 & 0.16 & 0.27 & 0.23 & 0.52 & 0.45 & 0.28 & 0.29 \\
$2 \mathrm{a}$ & 0.17 & 0.00 & 0.15 & 0.35 & 0.51 & 0.372 & 0.07 & 0.04 & 0.369 & 0.40 \\
$2 \mathrm{~b}$ & 0.01 & 0.31 & 0.30 & 0.16 & 0.15 & 0.40 & 0.41 & 0.21 & 0.34 & 0.44 & 0.35 \\
3 & 0.29 & 0.02 & 0.28 & 0.28 & 0.32 & 0.41 & 0.18 & 0.26 & 0.42 & 0.43 & 0.16 \\
\hline
\end{tabular}

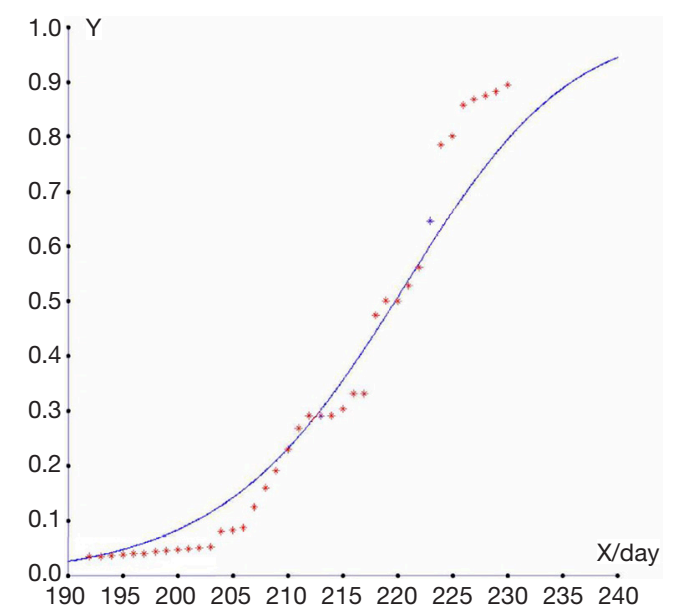

Figure 1 Possibility of classification into group 1 according to the diagnostic gestational age. Red points indicate the actual ratio.

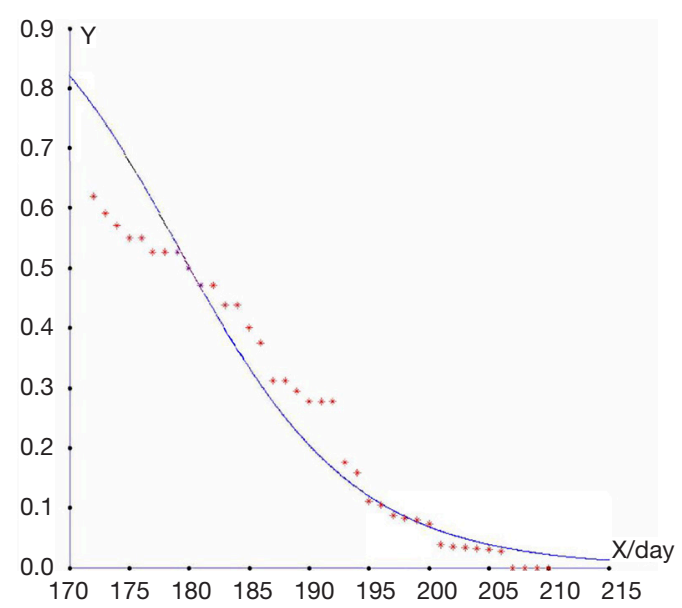

Figure 2 Possibility of classification into group 3 according to the diagnostic gestational age. Red points indicate the actual ratio.

In group 2a, the main factor was the 24-h urine protein level. In group $2 \mathrm{~b}$, the primary factor was prolongation, and the second factor was hydrothorax. In group 3, the primary factor was prolongation, the second factor was gestational age at delivery, and the tertiary factor was the plasma albumin level. Because prolongation and gestational age at delivery were the results of the other factors, the main factors were gestational age at diagnosis in group 1, the 24-h urine protein level in group 2a, hydrothorax and ascites in group $2 \mathrm{~b}$, and the plasma albumin level in group 3.

\section{Gestational age at diagnosis}

The multivariate regression analysis showed that the main factor in group 1 was gestational age at diagnosis. Using the Bayesian formula, we can use gestational age to determine whether or not the condition could be classified into group 1. Specifically, if we take $X$ as the gestational age at the time of diagnosis, then a condition that can be classified into group 1 is approximate to the following:

$$
\frac{22 \Phi\left(-\frac{X-172.2273}{23.9343}\right)}{22 \Phi\left(-\frac{X-172.2273}{23.9343}\right)+83 \Phi\left(\frac{X-202.55}{17.43}\right)}
$$

where $\Phi$ is the cumulative distribution function of $\mathrm{N}(0,1)$.

In the same way, a condition that can be classified into group 3 is approximate to the following:

$$
\frac{25 \Phi\left(-\frac{X-218.64}{19.31}\right)}{25 \Phi\left(-\frac{X-218.64}{19.31}\right)+81\left[1-\Phi\left(\frac{X-202.55}{17.43}\right)\right]}
$$

Finally, we compared this prediction to the outcomes of a real-life situation and calculated the accuracy of the discriminant method shown in Figures 1,2. The results showed that the higher the diagnostic gestational age was, the more likely the pregnancy would be categorized into group 3, and the less likely it would be categorized into group 1. The assumed probabilities conform to the actual statistics. When the gestational age at diagnosis was 25 weeks, and 4/7 days, the probability of categorization into group 1 was almost 50\%. Combined with gestational 
Table 4 The 24-h urine protein and plasma albumin levels in pregnancies with and without hydrothorax and ascites

\begin{tabular}{lccc}
\hline & $\begin{array}{c}24-\mathrm{h} \text { Urine } \\
\text { protein }(\mathrm{g})\end{array}$ & $\begin{array}{c}\text { Plasma } \\
\text { albumin }(\mathrm{g} / \mathrm{L})\end{array}$ & $\begin{array}{c}\text { Prolongation } \\
\text { (days) }\end{array}$ \\
\hline $\begin{array}{l}\text { With hydrothorax } \\
\text { and ascites }\end{array}$ & $8.614 \pm 6.132$ & $24.08 \pm 5.76$ & $14.34 \pm 10.99$ \\
$\begin{array}{l}\text { Without hydrothorax } \\
\text { and ascites }\end{array}$ & $5.829 \pm 5.501$ & $28.19 \pm 5.58$ & $22.16 \pm 20.87$ \\
\hline
\end{tabular}

age, the other $50 \%$ would be categorized into group 2 . When the gestational age at diagnosis was 27 weeks, and 1/7 days, approximately $20 \%$ of pregnancies were categorized into group 1, and the other $80 \%$ into group 2 . When the gestational age at diagnosis was 31 weeks, and 3/7 days, the probability that the patient would be categorized into group 3 was approximately $50 \%$. When the gestational age at diagnosis was 32 weeks, and $6 / 7$ days, the probability that the patient would be categorized into group 3 was $80 \%$. If the sample size had been larger, the fitting degree would have been higher.

\section{The relationship among 24-b urine protein, plasma albumin level, and ascites}

Similar to the above analysis, the main factors in the other groups were 24-h urine protein, hydrothorax, ascites, and albumin. All the participants were divided into two groups, defined as pregnancies with or without hydrothorax and ascites (Table 4). There were significant differences in the 24-h urine protein and plasma albumin levels between pregnancies with and without hydrothorax and ascites (both $\mathrm{P}<0.05$ ).

There was also a significant difference in the prolongation between pregnancies with and without hydrothorax and ascites, as presented in Table $4(\mathrm{P}<0.05)$. By Pearson's product-moment correlation, prolongation was correlated with the plasma albumin level $(\mathrm{P}<0.01)$ but not with the 24-h urine protein level $(\mathrm{P}=0.78)$, whose correlation degree was -0.328 . Among the three influencing factors, the plasma albumin level and hydrothorax and ascites affected prolongation, and an elevated 24-h urine protein level resulted in hydrothorax and ascites.

\section{Discussion}

Studies about early-onset severe preeclampsia have usually suggested that a poor pregnancy outcome occurs in combination with poor perinatal outcomes, such as neonatal mortality, respiratory distress syndrome (RDS), bronchopulmonary dysplasia (BPD), and intraventricular hemorrhage (IVH), and with maternal complications, such as antepartum HELLP, abruption placentae, pulmonary edema, DIC, and renal insufficiency (4,6-8). Additionally, it is difficult to evaluate the severities of different types of maternal and neonatal complications. This study designed a new approach for classifying pregnancy outcomes to explore the association and latency between early-onset severe preeclampsia characteristics and influencing factors.

Perinatal survival was associated with gestational age at delivery and birth weight, while the live birth rate was clearly related to gestational age at diagnosis of severe preeclampsia, which is in agreement with previous studies $(9,10)$. In this study, when the gestational age at diagnosis of severe preeclampsia was $\leq 24$ weeks, the live birth rate was $14 \%$. When the gestational age at diagnosis of severe preeclampsia was $\geq 25$ weeks, and $4 / 7$ days, the rate of the women classified into group 2 rose to $50 \%$. In the component analysis, gestational age at diagnosis was not important in either group 2 or group 3, and this occurred because most of the pregnancies that were affected by gestational age at diagnosis were classified into group 1. However, ACOG recommends that continuation of pregnancy in women with severe preeclampsia at less than 34 weeks and $0 / 7$ days of gestation be undertaken at facilities with maternal and neonatal intensive care resources and that pregnancy should be terminated only if severe preeclampsia occurs before 24 weeks. Given its unsatisfactory pregnancy outcomes, expectant management should be reconsidered before 25 weeks and $4 / 7$ days in China. This result may be affected by differing treatment levels of neonatal intensive care among different regions.

Regarding maternal complications, our data do not support previous findings that the urine protein level is related to the outcomes of pregnancies with preeclampsia. In this study, the 24-h urine protein and creatinine levels were not correlated by Pearson's product-moment correlation, which indicated that the urine protein level did not correlate with the deterioration of kidney function $(\mathrm{P}=0.33)$. Low plasma albumin levels and large amounts of hydrothorax and ascites correlated with extremely high 24-h urine protein levels. The plasma albumin level and hydrothorax and ascites should be taken more seriously because they may be the reason for the termination of expectant management of early-onset severe preeclampsia. However, reduced prolongation was associated with a reduction in plasma albumin levels and an increase in hydrothorax and 
ascites but not with an increase in the 24-h urine protein level. The 24-h urine protein level plays a role in the progression of preeclampsia to a certain degree by causing hypoproteinemia and hydrothorax plus ascites. The latter may increase the burden of cardiopulmonary function (11). These results are in agreement with those of previous studies (12-15).

There are more criteria that need to be taken into account, such as IUGR and the umbilical artery. However, this method is limited in that some factors are not included. In addition, the sample size is too small to obtain accurate results.

In summary, we have found that plasma albumin level and hydrothorax and ascites should be monitored closely, as they may lead to termination of the expected management of early-onset severe preeclampsia. Given its unsatisfactory pregnancy outcomes, expectant management should be reconsidered before 25 weeks and 4/7 days of gestational age.

\section{Acknowledgments}

None.

\section{Footnote}

Conflicts of Interest: The authors have no conflicts of interest to declare.

Ethical Statement: The authors are accountable for all aspects of the work in ensuring that questions related to the accuracy or integrity of any part of the work are appropriately investigated and resolved. This study was approved by the ethics review board of Renji Hospital affiliated with Shanghai Jiaotong University School of Medicine, and informed consent was obtained from every patient.

\section{References}

1. American College of Obstetricians and Gynecologists; Task Force on Hypertension in Pregnancy. Hypertension in pregnancy. Report of the American College of Obstetricians and Gynecologists' Task Force on Hypertension in Pregnancy. Obstet Gynecol 2013;122:1122-31.

2. Kalafat E, Thilaganathan B. Cardiovascular origins of preeclampsia. Curr Opin Obstet Gynecol 2017;29:383-9.

3. Armaly Z, Jadaon JE, Jabbour A, et al. Preeclampsia: Novel Mechanisms and Potential Therapeutic Approaches. Front Physiol 2018;9:973.

4. Shahul S, Ramadan H, Mueller A, et al. Abnormal mid-trimester cardiac strain in women with chronic hypertension predates superimposed preeclampsia. Pregnancy Hypertens 2017;10:251-5.

5. Magenes G, Bellazzi R, Fanelli A, et al. Multivariate analysis based on linear and non-linear FHR parameters for the identification of IUGR fetuses. Conf Proc IEEE Eng Med Biol Soc 2014;2014:1868-71.

6. Publications Committee, Society for Maternal-Fetal Medicine, Sibai BM. Evaluation and management of severe preeclampsia before 34 weeks' gestation. Am J Obstet Gynecol 2011;205:191-8.

7. Sarsam DS, Shamden M, Al Wazan R. Expectant versus aggressive management in severe preeclampsia remote from term. Singapore Med J 2008;49:698-703.

8. Haddad B, Deis S, Goffinet F, et al. Maternal and perinatal outcomes during expectant management of 239 severe preeclamptic women between 24 and 33 weeks' gestation. Am J Obstet Gynecol 2004;190:1590-5; discussion 1595-7.

9. Chawla S, Natarajan G, Shankaran S, et al. Association of Neurodevelopmental Outcomes and Neonatal Morbidities of Extremely Premature Infants With Differential Exposure to Antenatal Steroids. JAMA Pediatr 2016;170:1164-72.

10. Lemons JA, Bauer CR, Oh W, et al. Very low birth weight outcomes of the National Institute of Child health and human development neonatal research network, January 1995 through December 1996. NICHD Neonatal Research Network. Pediatrics 2001;107:E1.

11. Ashmore J, Attapattu JA. Massive ascites and bilateral hydrothorax complicating severe pre-eclampsia. Ceylon Med J 1998;43:235-7.

12. Sarno L, Maruotti GM, Saccone G, et al. Pregnancy outcome in proteinuria-onset and hypertension-onset preeclampsia. Hypertens Pregnancy 2015;34:284-90.

13. Bhide A, Rana R, Dhavilkar M, et al. The value of the urinary protein:creatinine ratio for the detection of significant proteinuria in women with suspected preeclampsia. Acta Obstet Gynecol Scand 2015;94:542-6.

14. Amaral LM, Wallace K, Owens M, et al. Pathophysiology and Current Clinical Management of Preeclampsia. Curr Hypertens Rep 2017;19:61.

15. Guida JPS, Surita FG, Parpinelli MA, et al. Preterm Preeclampsia and Timing of Delivery: A Systematic Literature Review. Rev Bras Ginecol Obstet 2017;39:622-31.

Cite this article as: Le Y, Ye J, Lin J. Expectant management of early-onset severe preeclampsia: a principal component analysis. Ann Transl Med 2019;7(20):519. doi: 10.21037/atm.2019.10.11 